\title{
Long-term effects of ocean acidification upon energetics and oxygen transport in the European sea bass (Dicentrarchus labrax, Linnaeus)
}

\author{
Crespel Amélie 1, ${ }^{*}$, Anttila Katja ${ }^{3}$, Lelièvre Pernelle ${ }^{1}$, Quazuguel Patrick ${ }^{1}$, Le Bayon Nicolas ${ }^{1}$, \\ Zambonino-Infante Jose-Luis ${ }^{1}$, Chabot Denis ${ }^{4}$, Claireaux Guy ${ }^{2}$ \\ ${ }^{1}$ Centre Ifremer de Bretagne, Unité PFOM-ARN, LEMAR UMR 6539Plouzané, France \\ 2 Université de Bretagne Occidentale, LEMAR UMR 6539, Centre Ifremer de Bretagne, Unité PFOM- \\ ARNPlouzané, France \\ 3 Department of BiologyUniversity of TurkuTurku, Finland \\ ${ }^{4}$ Maurice Lamontagne Institute, Fisheries and Oceans CanadaMont-Joli, Canada \\ * Corresponding author : Amélie Crespel, email address : amelie.crespel@gmail.com
}

\begin{abstract}
:
The accumulation of $\mathrm{CO} 2$ in the atmosphere and resulting ocean acidification represent a threat to marine ecosystems. While acid-base regulatory capacity is well developed in marine fish, allowing compensation of extra-cellular $\mathrm{pH}$ during short-term hypercapnia, the possible energetic costs of such regulation during long-term exposure remain to be established. In this study, juvenile European sea bass (Dicentrarchus labrax) were exposed from 2 days post-hatching to three different ocean acidification scenarios: control (present condition, $\mathrm{PCO} 2=520 \mu \mathrm{atm}, \mathrm{pH} 7.9)$, moderate acidification $(\mathrm{PCO} 2=950 \mu \mathrm{atm}, \mathrm{pH} 7.7)$, and high acidification $(\mathrm{PCO} 2=1490 \mu \mathrm{atm}, \mathrm{pH} 7.5)$. After 1.5 years of exposure, fish aerobic metabolic capacities, as well as elements of their oxygen extraction and transport chain, were measured. Compared to control, PCO2 treatments did not affect fish standard metabolic rate (SMR). However, the most severe acidification condition was associated with a significantly elevated maximum metabolic rate (MMR). This was supported by heavier gill system and higher blood haemoglobin concentration. A reduction of maximum cardiac frequency (fHmax) during incremental warming of anaesthetized fish was also observed in both acidification scenarios. On the other hand, the critical oxygen level (O2crit), the minimum oxygen level required to sustain SMR, did not differ among groups. The increased MMR, associated with maintained SMR, suggests that acid-base compensatory processes, although not increasing maintenance costs, may affect components of bass homeostasis, resulting in new internal physicochemical conditions. The possibility that these alterations influence metabolic pathways and physiological functions involved in fish aptitude to maximally transport oxygen is discussed.
\end{abstract}




\section{INTRODUCTION}

Over the last century, intensification of anthropogenic activities has led to increased carbon dioxide $\left(\mathrm{CO}_{2}\right)$ emissions (Intergovernmental Panel on Climate Change 2014) and atmospheric $\mathrm{CO}_{2}$ concentration is now reaching an unprecedented level in the last thousand year, in excess of 400 ppm (Lüthi et al. 2008). Oceans, which are representing $70 \%$ of the earth surface, absorb a large proportion of atmospheric $\mathrm{CO}_{2}$. When dissolved in water, $\mathrm{CO}_{2}$ chemically reacts to produce carbonic acid $\left(\mathrm{H}_{2} \mathrm{CO}_{3}\right)$ which then dissociates into bicarbonate ions $\left(\mathrm{HCO}_{3}{ }^{-}\right)$and protons $\left(\mathrm{H}^{+}\right)$. The increased concentration of protons in the world oceans is now a widely recognized phenomenon named 'ocean acidification' (OA).Since the beginning of the twentieth century, ocean surface pH has already declined by $0.1 \mathrm{U}$ (Intergovernmental Panel on Climate Change 2014) and projections suggest an additional decrease of 0.3 to $0.5 \mathrm{U}$ by 2100 (Caldeira and Wickett 2005; Intergovernmental Panel on Climate Change 2014).

Ocean acidification and related changes in marine water's chemistry are recognized to have negative effects on the survival, calcification, growth and reproduction of many calcifying marine organisms such as corals, echinoderms and bivalves (Kroeker et al. 2010; Kroeker et al. 2013). Available information regarding the impact on fish leans toward an absence of effect due to their acid-base regulatory capacity, which is believed to exceed what is required to face the predicted acidification of their environment (Heuer and Grosell 2014). However, whereas the mechanistic bases of acid-base regulation are well described in fish (Pörtner et al. 2004; Heuer and Grosell 2014), this knowledge is not yet matched with a full understanding of the implications for fish populations in their natural environment. One missing piece of information relates to the potential long term consequences of ocean acidification and in particular its cumulative effects over life stages on integrated processes such as, for instance, energy metabolism, ontogeny and growth. To 
our knowledge, only one study has investigated the long term (14-16 weeks) effect of hypercapnia at ecologically relevant level (1000 $\mu \mathrm{atm})$ (Gräns et al. 2014). Using the Atlantic halibut (Hippoglossus hippoglossus, Linnaeus), these authors revealed impaired growth (only at cold temperature, $4^{\circ} \mathrm{C}$ ) but increased aerobic metabolic scope at every tested temperature (ranging from $4^{\circ} \mathrm{C}$ to $18^{\circ} \mathrm{C}$ ), the latter suggesting that fish aerobic performance was not compromised by longterm exposure to elevated ambient $\mathrm{CO}_{2}$. However, these authors also pointed out that the causal link between oxygen supply and whole-animal performance and fitness under hypercapnic conditions remained unclear and needed further investigation.

The notion of capacity for aerobic metabolic activities (also named aerobic metabolic scope), put forth by Fry (1971), has been proposed as a useful measure to investigate the influence of the environment upon fish performance (for review see Claireaux and Lefrançois 2007). According to Fry's original definition, the aerobic metabolic scope is the difference between the standard metabolic rate (SMR, the cost of maintenance measured in unstimulated, inactive and fasted fish, Chabot et al., 2016) and the maximal metabolic rate (MMR). The aerobic metabolic scope therefore quantifies the capacity of a given fish, in a given set of environmental conditions, to allocate energy to physiological activities beyond SMR (such as digestion, growth, locomotion and reproduction) and represents an integrative approach to examine the physiological basis of environmental adaptation (Claireaux and Lefrançois 2007). On that basis, it has been predicted that the anticipated increase in marine $\mathrm{CO}_{2}$ levels will contribute to reduce fish capacity for aerobic activities (Pörtner and Farrell 2008), with expected impacts upon individual's fitness and, ultimately, upon the resilience of populations. Yet, literature reviews shows that reported effects of near-future hypercapnia on fish aerobic capacity are contrasted (Lefevre 2016; Esbaugh 2018; Hannan and Rummer 2018), with an increased aerobic metabolic scope observed in damselfish (Acanthochromis 
polyacanthus, Bleeker) (Rummer et al. 2013) or no effect in Atlantic cod (Gadus morhua,

Linnaeus) (Melzner et al. 2009).

According to the Fick equation, the aerobic metabolic rate of an animal is a function of its capacity to extract oxygen from the ambient water and to deliver it to the ATP-producing mitochondria (Farrell et al. 2014). The heart therefore represents a key component of the Fick equation as it determines internal oxygen fluxes and allocation among the circulatory beds. Accordingly, using an in situ heart preparation, Gräns et al. (2014) observed that the maximum flow-generating capacity of Atlantic halibut heart increased under hypercapnia. The gill is also an important component of the Fick equation as it is the main site of oxygen extraction from the ambient water (Evans et al. 2005). It has long been demonstrated that a relationship exists between gill surface area and fish metabolic demand for oxygen and maximum metabolic rate (Schmidt-Nielsen 1997). Blood oxygen carrying capacity is as well a crucial component of the oxygen transport and delivery chain. However, a previous study reported a reduced blood oxygen contentin species maintained under rather severe hypercapnic condition (40 $000 \mu \mathrm{atm}$; McKenzie et al. 2003), possibly limiting aerobic capacity. Nevertheless, there exist to date no integrated long term study of the components of the oxygen transport chain under predicted capnic conditions and following long term exposure and compensation.

Oxygen availability is an important environmental issue for aquatic organisms. Classically, the capacity of these organisms to tolerate an episode of reduced oxygen availability (hypoxia) is assessed by measuring the critical oxygen level $\left(\mathrm{O}_{2 \text { crit }}\right)$ i.e., the oxygen threshold below which SMR is no longer sustainable aerobically. Below this threshold, some of the ATP must be produced anaerobically and/or metabolic depression takes place (Nilsson and Renshaw 2004).With the predicted global warming, hypoxic events are expected to become more frequent and more severe 
119 (Intergovernmental Panel on Climate Change 2014; Rogers et al. 2016). Yet, very few studies have

120 investigated the potential interaction between projected ocean acidification and deoxygenation in

121 fish. These few studies report, however, no effect on $\mathrm{O}_{2 \text { crit }}$ after both short-term (four days) or

122 following long-term (six weeks) exposure to hypercapnia in two damselfish, Pomacentrus

123 moluccensis (Bleeker) and Pomacentrus amboinensis (Bleeker), (Couturier et al. 2013) and in the

124 European eel, Anguilla Anguilla (Linnaeus), (McKenzie et al. 2003).

125

126

127

128

129

130

131

132

133

134

135

Animals

In this context, the objective of the present study was to investigate the effect of a long-term exposure to elevated water $\mathrm{CO}_{2}$ content upon the energetics and oxygen transport capacity of a commercially relevant, temperate fish, the European sea bass (Dicentrarchus labrax, Linnaeus). In this experiment, the possibility of carry-over effects of early environmental conditions across life history stages was taken into consideration (Vanderplancke et al. 2015). Accordingly, fish were maintained under hypercapnia from two days post-hatch and untilthey were 1.5 -year old. Three $\mathrm{P}_{\mathrm{CO} 2}$ treatments were tested i.e., control $\left(\mathrm{P}_{\mathrm{CO} 2}=520 \mu \mathrm{atm}\right)$, moderate acidification $\left(\mathrm{P}_{\mathrm{CO} 2}=950\right.$ $\mu \mathrm{atm})$ and high acidification $\left(\mathrm{P}_{\mathrm{CO} 2}=1490 \mu \mathrm{atm}\right)$. The specific objectives of our study were (1) to examine the influence of hypercapnia on aerobic performance (SMR and MMR) through respirometry measurements, (2) to evaluate simple determinants of fish capacity for oxygen extraction and transport such as cardiac and gill masses to body mass ratios, maximal heart rate (on anaesthetized fish) as well as blood haematocrit and haemoglobin concentration, and (3) to measure the critical oxygen level as an index of hypoxia tolerance.

\section{MATERIALS AND METHODS}


Fish were obtained in October 2013 from a local commercial hatchery (Aquastream, Ploemeur, France). At two days post-hatch (dph), they were brought to Ifremer rearing facility (Brest, France) and randomly distributed among nine tanks $\left(38 \mathrm{~L} ; 19^{\circ} \mathrm{C} ; \mathrm{n}=2200\right.$ larvae per tank) corresponding to three experimental treatments in triplicates i.e., control (labelled $C ; \mathrm{pH}$ total 7.9; $\mathrm{P}_{\mathrm{CO} 2}=520 \mu \mathrm{atm}$ ), moderate acidification $\left(M A ; \mathrm{pH}\right.$ total $\left.7.7 ; \mathrm{P}_{\mathrm{CO} 2}=950 \mu \mathrm{atm}\right)$ and high acidification $(H A ; \mathrm{pH}$ total 7.5; $\left.\mathrm{P}_{\mathrm{CO} 2}=1490 \mu \mathrm{atm}\right)$. The photoperiod was set at $16 \mathrm{~h}$ light: $8 \mathrm{~h}$ dark. Larvae were fed ad libitum with Artemia until 28 dph and then with commercial pellets according to feeding charts (about $1 \%$ ration, w/w, Néo-start and néo-grower, Le Gouessant, France). At 45 dph, some fish within each treatment were pooled and transferred to three larger tanks (450 L, n= 1500 fish per tank) with identical water $\mathrm{P}_{\mathrm{CO} 2}$ and $\mathrm{pH}$ as above. At that time, there was no tank replication within the treatments but special care was taken to standardize every rearing conditions. Temperature was set at $15{ }^{\circ} \mathrm{C}$ (Table 1) and photoperiod followed the natural day-night cycle. When fish reached approximately $10 \mathrm{~g}$ (about 8 months), 700 fish per condition were anaesthetized with tricaine methane sulphonate (MS222, Pharmaq, UK) and a passive integrated transponder (PIT tag;ISO $1.4 \mathrm{~mm} \times 9 \mathrm{~mm}$, Biolog-id, France) was inserted subcutaneously behind the dorsal fin. No difference in the mortality was observed among the conditions from the larval (Crespel et al. 2017) to the juvenile stage. Fish were unfed for $24 \mathrm{~h}$ before any manipulation or experiment. The protocol was in conformity with current rules and regulations in France (project code: APAFIS 4341.03, \#201620211505680.V3).

\section{Experimental conditions}

Experimental conditions were obtained using an automatic $\mathrm{CO}_{2}$ injection system connected by a $\mathrm{pH}$ electrode (pH Control, JBL, Germany). Salinity (WTW LF325, Xylem Analytics Germany, Weilheim, Germany) was measured monthly. A daily control of water temperature and $\mathrm{pH}$ 
169 (National Bureau of Standards scale, $\mathrm{pH}_{\mathrm{NBS}}$ ) was performed every morning before feeding with a 170 hand held pH meter (330i, WTW, Germany) calibrated daily with fresh certified WTW technical 171 buffers pH 4.01 an pH 7.00 (Xylem Analytics Germany, Weilheim, Germany). In addition, total pH 172 was determined monthly following Dickson et al. (2007) using m-cresol purple as the indicator.

173 Total alkalinity (TA) in each tank was measured monthly by titration (Labocea, France). Phosphate 174 and silicate concentrations were determined by segmented flow analysis following Aminot et 175 al.(2009). $\mathrm{CO}_{2}$ partial pressure $\left(\mathrm{P}_{\mathrm{CO} 2}\right)$ was calculated using the total $\mathrm{pH}$ measurements and the 176 Microsoft excel macro CO2SYS software (Lewis and Wallace 1998) and constants from Mehrbach 177 et al. (1973). Water chemistry is summarized in Table 1.

\section{Respirometry}

Experimental set-up

Fish oxygen uptake $\left(\mathrm{MO}_{2}\right)$ was measured using eight static, intermittent flow respirometry thermoregulated $\left(15 \pm 0.25^{\circ} \mathrm{C}\right)$ seawater. Water $\mathrm{P}_{\mathrm{CO} 2}$ was regulated at the level of the fish original rearing tank using the same automatic $\mathrm{CO}_{2}$ injection system as described above. The respirometry system was placed behind an opaque curtain and movements in and out of the room were kept to a minimum to prevent fish disturbance. Submersible pumps (Eheim $\mathrm{GmbH}$, Germany) supplied water from the outer tank to the respirometer chambers. These pumps were controlled by Aquaresp software (aquaresp.com) which set the frequency and duration of the open (flush) and closed 191 (measure) modes of the measuring cycle. A second series of pumps (Eheim GmbH, Germany) 192 connected, via a closed circuit, an optode (PreSens GmbH, Germany or Firesting Pyro Science, 193 Germany) to the respirometry chambers. This closed circuit allowed the monitoring of the oxygen 
194 level in the chambers (\% air saturation) and insured good mixing of water in each respirometer.

195 Optodes were calibrated before each respirometry trials using fully aerated water and a $0 \%$ oxygen 196 solution (sodium sulfite in excess).

197 The rate of oxygen consumption $\left(\mathrm{MO}_{2}\right.$, in $\left.\mathrm{mg} \mathrm{O}_{2} \mathrm{~h}^{-1} \mathrm{~kg}^{-1}\right)$ was calculated by Aquaresp software 198 using the following formula:

$\mathrm{MO}_{2}=\mathrm{a} \times \beta \times \mathrm{V}_{\mathrm{rem}} / \mathrm{mf}$

where $\mathrm{a}$ is the slope of the decrease in water oxygen level over time $\left(\% \mathrm{O}_{2}\right.$ saturation $\left.\mathrm{h}^{-1}\right), \beta$ is the solubility of $\mathrm{O}_{2}\left(\mathrm{mg} \mathrm{O}_{2} \mathrm{~L}^{-1} 100 \% \mathrm{O}_{2}\right.$ saturation $\left.^{-1}\right), \mathrm{V}_{\text {rem }}$ is the volume of the chamber minus the volume of the fish (L) and $\mathrm{mf}$ is the fish mass $(\mathrm{kg})$.

Respirometry protocol

Experiments were conducted from February to April 2015. Fish mean mass was $79.6 \pm 1.7 \mathrm{~g}$ and mean length was $18.1 \pm 0.1 \mathrm{~cm}(\mathrm{n}=24$ per acclimation group, no statistical differences between groups, ANOVA, $F(2,69)=1.439, P=0.244$, ANOVA, $F(2,69)=0.960, P=0.387$, respectively). A typical respirometry trial is presented in Fig.1. Fish were fasted three days prior to measurements to prevent residual specific dynamic action (Jourdan-Pineau et al. 2010). Three sets of eight fish per experimental treatment were tested in three blocks and all treatments were tested once per block in systematic order (C, MA, HA). The three blocks were completed in 30 days. For each run, eight fish were selected at random from the treatment tanks, identified (PIT tag reading) and their mass and length measured. They were then placed in a $10 \mathrm{~L}$ tank where they were manually chased, typically less than 10 minutes, until exhaustion i.e., they would not respond to further stimulation. The fish were then rapidly placed in a respirometer chamber and the oxygen consumption measurement 
immediately started (Zhang et al. 2018). The respirometry cycle included $210 \mathrm{~s}$ in closed mode (measurement) followed by $90 \mathrm{~s}$ of open mode (chamber flushing). The first $30 \mathrm{~s}$ in closed mode (wait period) were not used to calculate fish oxygen consumption to insure that the decrease in $\mathrm{O}_{2}$ with time had become linear. Therefore, only the last $180 \mathrm{~s}$ of the slope was used for each measurement of oxygen uptake. The highest oxygen uptake measured during the $2 \mathrm{~h}$ postexhaustion recovery period (obtained during the first 30 minutes) was used to estimate fish maximum metabolic rate (MMR). At $2 \mathrm{~h}$ post-exhaustion, as fish had partially recovered from exhaustion and $\mathrm{MO}_{2}$ was approximately half of the maximal value, the respirometry measuring cycle was modified with $360 \mathrm{~s}$ in closed mode (30 s wait and $330 \mathrm{~s}$ for measurement) and $240 \mathrm{~s}$ of chamber flushing. These conditions were maintained during at least the next $65 \mathrm{~h}$, allowing a reliable estimation of fish standard metabolic rate (SMR) (Chabot et al. 2016). Note that during $\mathrm{MO}_{2}$ measurements, water oxygen level in the respirometers never dropped below $75 \%$. The last phase of each experimental trial was dedicated to estimating fish critical oxygen level $\left(\mathrm{O}_{2 \text { crit }}\right)$. To this end, the water in the outer tank was deoxygenated by passing through a gas equilibration column supplied with nitrogen before it was pumped into the respirometers. Water oxygen level in the respirometry chambers was dropped from $100 \%$ air saturation (\% air sat) to approximately $8 \%$ air sat over a period of 4-5 hours during which fish oxygen consumption continued to be monitored using the same measurement cycle as before (Claireaux and Chabot 2016). At the end of the hypoxic trial, fish were removed from the respirometry chambers and returned to their original rearing tank. Background bacterial $\mathrm{MO}_{2}$ was then recorded in the empty chambers and estimated at every time during the experiment using linear regression, assuming zero background respiration at the beginning of the run as the entire system was disinfected with household bleach between each trial. Each fish $\mathrm{MO}_{2}$ measurement was then corrected for the calculated background respiration. 
Respirometry data analysis and calculations

The accuracy of the $\mathrm{MO}_{2}$ estimation is reflected by the regression coefficient $\left(\mathrm{R}^{2}\right)$ between water oxygen level and time during the measurement period (closed mode) of the respirometry cycle. Values of $\mathrm{MO}_{2}$ associated with $\mathrm{R}^{2}$ below 0.85 were removed from the analysis (maximum $5 \%$ in some fish). MMR was determined using the highest $\mathrm{MO}_{2}$ values recorded during the 2-h post exhaustion period. Fish SMR was determined using a R script (Chabot et al., 2016) and $\mathrm{MO}_{2}$ measurements obtained after fish full recovery (typically $10 \mathrm{~h}$ ) and before the beginning of the hypoxia treatment. Briefly, the script analyses the distribution of $\mathrm{MO}_{2}$ measurements (mclust function in $\mathrm{R}$ package) and selects the number of normal distributions that best fit the data (between one and four). The coefficient of variation $(\mathrm{CV})$ of the values assigned to the normal distribution with the lowest mean value among the four distributions is then calculated. When CV is below 7 the mean of the values assigned to the lowest normal distribution is considered to represent SMR. When CV is more than 7, the 0.2 quantile of the values is preferred to represent SMR (Chabot et al. 2016).

The critical oxygen level $\left(\mathrm{O}_{2 \text { crit }}\right)$ was determined using a $\mathrm{R}$ script from Claireaux and Chabot (2016). This script establishes the linear regression between the ambient oxygen level and fish $\mathrm{MO}_{2}$ as hypoxic conditions develop. The calculated intersection between this regression line and SMR corresponds to $\mathrm{O}_{2 \text { crit }}$ (Fig. 2).

\section{Maximum heart rate}

Measurement of maximum heart rate $\left(f_{\text {Hmax }}\right)$ were performed during September 2014, following Casselman et al. (2012). At that time fish weighted $30.1 \pm 1.0 \mathrm{~g}$ and were $13.5 \pm 0.1 \mathrm{~cm}$ in length (no 
statistical differences between experimental treatments, ANOVA, $F(2,39)=1.643, P=0.207$, ANOVA, $F(2,39)=0.114, P=0.738$, respectively).

The fish ( $\mathrm{N}=14$ per treatment) were anesthetized in $32 \mathrm{ppm}$ seawater containing $5 \mathrm{mgL}^{-1} \mathrm{MS} 222$, the $\mathrm{pH}$ was adjusted with $\mathrm{NaOH}$ to similar $\mathrm{pH}$ as in the experimental treatments. After being weighted, fish were placed in an experimental setup that received aerated and temperature controlled water containing a maintenance dose of MS222 $\left(5 \mathrm{mgL}^{-1}\right)$. At the beginning of the experiment the water temperature was $17^{\circ} \mathrm{C}$. The water was partially directed over the fish gills. Fish electrocardiogram (ECG) was detected with silver electrodes positioned on the skin just above and below the heart, a ground electrode was in the water. The ECG was recorded with BioPac MP36R (BIOPAC Systems Inc, Essen, Germany) with build-in amplifiers and filters.

Fish were allowed to stabilize in the setup for 30 minutes before intraperitoneal injections of atropine sulphate $\left(3 \mathrm{mgkg}^{-1}\right)$ and isoproterenol $\left(8 \mathrm{\mu kg}^{-1}\right)$ to increase heart rate to its maximum value $\left(f_{\text {Hmax }}\right)($ Casselman et al. 2012). Both drugs were purchased from Sigma-Aldrich Chemie Gmbh (Munich, Germany) and dissolved in saline $(0.9 \% \mathrm{NaCl})$. The time-interval between injections was 15 minutes after which the temperature of water was increased in $1^{\circ} \mathrm{C}$ increments every six minutes $\left(10^{\circ} \mathrm{Ch}^{-1}\right)$. At each step, the heart rate was allowed to stabilize for five minutes. $f_{\text {Hmax }}$ was recorded at each temperature increment by measuring the duration of 15 heart beats $\mathrm{R}-\mathrm{R}$ intervals and transforming into a frequency. When cardiac arrhythmias (missing QRS complex in ECG signal i.e. atrioventricular block, see Anttila et al. 2013) were first observed the temperature of the water was recorded (=arrhythmia temperature, $\mathrm{T}_{\mathrm{ARR}}$ ), fish were removed from setup and returned to their rearing tank. No mortalities were observed during the days that followed the trials. 
292 For each fish the Arrhenius break point temperature $\left(\mathrm{T}_{\mathrm{AB}}\right)$, was calculated using Arrhenius plots 293 according to Yeager and Ultsh (1989). The analyses were done with SigmaPlot (12.3; Systat 294 Software Inc., USA) Regression Wizard program using two segment linear regression formula. In 295 the analyses the temperature was transformed to Kelvins and expressed in $\mathrm{x}$-axis while heart rate 296 was transformed to natural logarithm of $f_{\mathrm{Hmax}}$ and expressed in y-axis. The plot included all the 297 testing temperatures and heart rates from $17^{\circ} \mathrm{C}$ until arrhythmias were observed. The software fitted 298 two linear regression lines to plot and the intersection of the two linear regression lines indicated the 299 Arrhenius break point temperature $\left(\mathrm{T}_{\mathrm{AB}}\right)$.

\section{Samplings} the ventricle mass by total body mass.

Blood haemoglobin concentration was measured with a colorimetric kit (Drabkin, Sigma, France). 
calculation of the gill water content. Gill-somatic index was obtained dividing the gill filaments mass by the total body mass.

\section{Statistical analysis}

Data normality and homogeneity were tested with analysis of the distribution of the residuals and Levene tests respectively. A general linear model was used to analyse MMR, SMR, aerobic scope

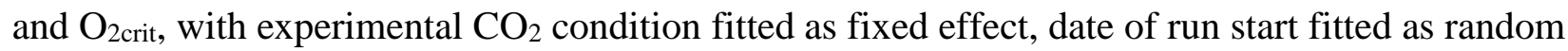
effect and body mass as a covariate. A two-way repeated measures of ANOVA was used to analyse $f_{\text {Hmax }}$ differences between experimental $\mathrm{CO}_{2}$ conditions and measuring temperatures. Mass, $\mathrm{T}_{\mathrm{AB}}$, $\mathrm{T}_{\mathrm{ARR}}$, gill, heart and blood data (gill-somatic index, gill water content, ventriculo-somatic index, haematocrit, haemoglobin concentration, MCHC) were analyzed using one-way ANOVAs with experimental $\mathrm{CO}_{2}$ condition as factor. The Bonferonni correction was applied to the haematocrit, haemoglobin concentration and MCHC. A posteriori Tukey's tests were performed when variances were homogenous, otherwise, Games \& Howell test was preferred.Statistical analyses were performed using Statistica7 (Statsoft, USA) and SigmaPlot 12.3 (Systat Software Inc., USA). A significance level of $\alpha=0.05$ was used in all statistical tests.

\section{RESULTS}

\section{Respirometry}

Experimental $\mathrm{CO}_{2}$ treatments had no significant effect on SMR $(\operatorname{GLM}, F(2,6)=0.681, \mathrm{P}=0.542)$ (Fig. 3) but significantly affected MMR $(\mathrm{GLM}, F(2,6)=4.414, \mathrm{P}=0.016)$. Fish exposed to severe hypercapnia (HA) had a significantly higher MMR than control (C) and moderate hypercapnic 
341 (MA) fish (Fig. 3). No significant difference between $\mathrm{C}$ and MA fish was observed. Experimental $342 \mathrm{CO}_{2}$ treatments had no significant effect on aerobic metabolic scope $(\mathrm{GLM}, F(2,6)=0.664, \mathrm{P}=$ 343 0.549), which was $231.9 \pm 7.4 \mathrm{mgO}_{2} \mathrm{~h}^{-1} \mathrm{~kg}^{-1}, 237.0 \pm 6.4 \mathrm{mgO}_{2} \mathrm{~h}^{-1} \mathrm{~kg}^{-1}$ and $254.2 \pm 11.1 \mathrm{mg} \mathrm{O}_{2} \mathrm{~h}^{-1} \mathrm{~kg}^{-1}$ for 344 the C, MA and HA fish respectively. Body mass covariate was having a significant effect on SMR $345(\mathrm{GLM}, F(2,6)=8.62, \mathrm{P}=0.005)$ and on MMR $(\mathrm{GLM}, F(2,6)=7.46, \mathrm{P}=0.008)$, but not on the 346 aerobic metabolic scope $(\mathrm{GLM}, F(2,6)=3.24, \mathrm{P}=0.077)$. The body mass of the fish was ranging 347 from $53.7 \mathrm{~g}$ to $118.5 \mathrm{~g}$, the mean being $79.6 \pm 1.7 \mathrm{~g}$.

Maximum heart rate measurements

During warming, both the experimental $\mathrm{CO}_{2}$ treatments and water temperature had significant effects on $f_{\text {Hmax }}\left(\right.$ ANOVA, $F(2,344)=13.6, \mathrm{P}<0.001$ for $\mathrm{CO}_{2}$ and $F(10,344)=3.2, \mathrm{P}<0.001$ for temperature) as no interaction between the main factors was found (ANOVA, $F(2,10)=0.48, \mathrm{P}=$ 0.97). A posteriori tests revealed that there were significant differences between $\mathrm{C}$ and MA fish and between $\mathrm{C}$ and HA fish while the MA and HA fish did not differ significantly from each other. The control group had the highest $f_{\text {Hmax }}$ values during warming, whereas exposure to hypercapnic conditions lowered the maximum heart rate significantly (Fig.4).

Although heart rate measured during warming was lowered in hypercapnic-reared fish, thermal tolerances $\left(\mathrm{T}_{\mathrm{AB}}\right.$ : ANOVA, $F(2,40)=0.006, \mathrm{P}=0.99$, and $\mathrm{T}_{\mathrm{ARR}}$ : ANOVA, $F(2,40)=0.53, \mathrm{P}=$ 0.59) were not found statistically different among rearing $\mathrm{CO}_{2}$ treatments (Table 2).

\section{Tissues and blood response}


The experimental $\mathrm{CO}_{2}$ treatments had no significant effect on the ventriculo-somatic index $($ ANOVA, $F(2,21)=0.93, \mathrm{P}=0.41)($ Table 3$)$.

Rearing $\mathrm{CO}_{2}$ conditions had a significant influence upon the wet (data not shown) and dry gill mass/body mass ratio (Fig.5A) (ANOVA, $F(2,21)=3.8, \mathrm{P}=0.039$ and $F(2,21)=6.6, \mathrm{P}=0.006$, respectively). This ratio was significantly higher in HA fish compared to C fish while MA fish were similar to both $\mathrm{C}$ and $\mathrm{HA}$ fish. Rearing $\mathrm{CO}_{2}$ conditions also had a significant influence upon gill water content $(\mathrm{ANOVA}, F(2,21)=4.1, \mathrm{P}=0.032)$. Gill water content was significantly lower in HA fish compared to MA fish (Fig. 5B) whereas control fish were similar to both MA and HA fish.

No significant difference in blood haematocrit was observed among the three experimental $\mathrm{CO}_{2}$ groups (ANOVA, $F(2,21)=1.0, \mathrm{P}=0.38$, Bonferroni correction $\mathrm{P}=1)($ Table 3$)$. However, experimental $\mathrm{CO}_{2}$ treatments had a significant influence upon blood haemoglobin concentration $($ ANOVA, $F(2,21)=6.9, \mathrm{P}=0.005$, Bonferroni correction $\mathrm{P}=0.015)($ Table 3$)$ which was significantly higher in HA fish compared to $\mathrm{C}$ and MA fish. No difference between $\mathrm{C}$ and MA was observed. The resulting mean corpuscular haemoglobin concentration (MCHC) differed among experimental $\mathrm{CO}_{2}$ groups $(\mathrm{ANOVA}, F(2,21)=12.1, \mathrm{P}<0.001$, Bonferroni correction $\mathrm{P}=0.003$ ) (Table 3). Higher MCHC levels were observed in HA and MA fish compared to the $\mathrm{C}$ fish. No difference between HA and MA was observed.

\section{Critical oxygen level}

No significant difference among experimental treatments was observed on $\mathrm{O}_{2 \text { crit }}$ (GLM, $F(2,6)=0.509, \mathrm{P}=0.625)($ Table 3$)$. 


\section{DISCUSSION}

The objective of this study was to examine the integrated consequences of exposing fish to projected ocean acidification conditions over a 1.5-year period which included larval and juvenile life stages. In this study, fish aerobic metabolic capacity (SMR, MMR, aerobic metabolic scope and critical oxygen level) as well as characteristics of the oxygen extraction and transport chain (namely maximal heart rate, gill and ventricular mass, blood haematocrit and haemoglobin concentration) were measured. Compared to the control treatment ( $C$; pH 7.9, PCO2: $520 \mu \mathrm{atm})$, moderate acidification conditions (MA; $\left.\mathrm{pH} 7.7, \mathrm{P}_{\mathrm{CO} 2}: 950 \mu \mathrm{atm}\right)$ had no effect on the fish aerobic metabolic capacity nor gill mass to body mass ratio. However, the cardiac response to the acute increase in water temperature was altered as values of maximal heart rate were significantly lower. In the high acidification condition ( $\left.H A ; \mathrm{pH} 7.5, \mathrm{P}_{\mathrm{CO} 2}: 1490 \mu \mathrm{atm}\right)$, no difference in fish standard metabolic rates was observed but higher maximal metabolic rates were measured. Despite these results, no significant difference in aerobic metabolic scope was found, likely as a result of high interindividual variability in both variables. Fish from this condition also presented a heavier gill system, as well as higher haemoglobin concentration and mean corpuscular haemoglobin concentration, suggesting higher oxygen extraction and transport capacity, even if they also presented a reduced maximal heart rate during warming. However, these fish displayed similar critical oxygen level to control fish. Overall, these results suggest that projected high acidification condition can lead to a new aerobic metabolic condition in sea bass (Dicentrarchus labrax, Linnaeus) juveniles.

A 1.5-year exposure to $\mathrm{P}_{\mathrm{CO} 2}$ levels above current situation $(950 \mu \mathrm{atm}$ and $1490 \mu \mathrm{atm})$ did not affect sea bass standard metabolic rate. Conflicting data exist in the literature regarding the effect of hypercapnia on SMR. A similar lack of effect has been reported in Atlantic Cod (Gadus morhua, 
415 Linnaeus, acclimated to extreme hypercapnia ,6000 $\mu \mathrm{atm}$, for 12 months, Melzner et al. 2009) and 416 in damselfish (Pomacentrus moluccensis, Bleeker, and Pomacentrus amboinensis, Bleeker,

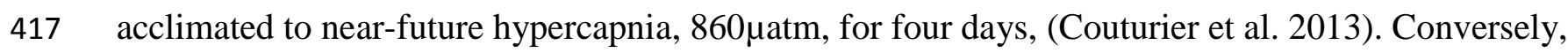
418 spiny damselfish (Acanthochromis polyacanthus, Bleeker, exposed to $946 \mu$ atm $\mathrm{P}_{\mathrm{CO} 2}$ for 17 days) 419 displayed lower resting metabolic rate (Rummer et al. 2013). Such discrepancies in fish responses 420 to hypercapnia prevents definitive conclusion. However, the diversity in experimental conditions 421 tested in the above studies may explain, at least partially, the variability in the reported effects.

422 Exposure duration is certainly an important element to take into account. Fish exposed to hypercapnic conditions must restore internal acid-base balance by pumping bicarbonate from the surrounding water mostly in exchange for chloride. This entry of bicarbonate compensates $\mathrm{CO}_{2}$ related acidosis by restoring extra-cellular $\mathrm{pH}$ and, depending on the species and experimental conditions tested, these adjustments may take from hours to days to be completed (Esbaugh et al. 2012; Heuer and Grosell 2014). Thus, measures of $\mathrm{MO}_{2}$ made within a few days following exposure may not represent true SMR as they may include the masking effect of this additional regulatory work. In addition, in some of the previous studies, unusual respirometry protocols were used such as recording SMR during daytime, the later potentially leading, in diurnal species, to an overestimation of SMR due to residual activity and vigilance. As also pointed out by Gräns et al. (2014), this may potentially result in increased inter-individual variability in SMR masking the modest cost of acid-base compensation.

The similar standard metabolic rate observed among experimental treatments suggests that long term acclimation to even the most severe ocean acidification scenario did not affect sea bass maintenance demand for oxygen. It remains to be determined, however, whether this observation implies no additional regulatory costs or rather that the additional cost is compensated through, for 
reported increased homeostasis-related activities such as ion transports, acid-base regulation and energy metabolism enzymes following long term (>14 weeks) exposure to high $\mathrm{P}_{\mathrm{CO} 2}$ levels (Evans et al. 2005; Esbaugh et al. 2012; Bresolin de Souza et al. 2014). It was then hypothesized that these increased activities should lead to increased SMR (Deigweiher et al. 2010; Bresolin de Souza et al. 2014; Esbaugh 2018; Hannan and Rummer 2018) but the few published studies that actually measured the cost of hypercapnia suggested that exposure to hypercapnia was not associated with increased metabolic expenditure (Deigweiher et al. 2008; Melzner et al. 2009; Esbaugh et al. 2016; Lefevre 2016). The absence of difference in growth in the present study additionally supports the lack of energetic cost of future hypercapnia. As mentioned above, revised trade-off among the life sustaining functions may contribute to preserve SMR under hypercapnic conditions. To our knowledge, however, no published information is available to document this possible change in fish prioritisation of physiological functions.

In the current study, the long-term exposure to high $\mathrm{CO}_{2}$ level $(1490 \mu \mathrm{atm})$ resulted in significantly elevated MMR (+10\%). Previous studies also reported increased MMR ( 20\%) in the spiny damselfish (Acanthochromis polyacanthus, Bleeker, exposed to $946 \mu$ atm $\mathrm{P}_{\mathrm{CO} 2}$, Rummer et al. 2013 ) and (28-39\%) in the damselfish (Pomacentrus amboinensis, Bleeker, exposed to $860 \mu \mathrm{atm}$ $\mathrm{P}_{\mathrm{CO} 2}$, Couturier et al. 2013). On the contrary, in a different species of damselfish (Pomacentrus moluccensis, Bleeker), as well as in its predator (Pseudochromis fuscus, Muller and Troschel) no change in MMR was observed (exposure to $860 \mu \mathrm{atm} \mathrm{P}_{\mathrm{CO} 2}$, Couturier et al. 2013). Lack of effect has also been reported in the European eel (Anguilla anguilla, Linnaeus, exposed up to 60000 $\mu$ atm $\mathrm{P}_{\mathrm{CO} 2}$, McKenzie et al. 2003), in the Atlantic Cod (Gadus morhua,Linnaeus, exposed to $6000 \mu \mathrm{atm}$ $\mathrm{P}_{\mathrm{CO} 2}$, Melzner et al. 2009), . As for SMR, these differences are likely at least partially the result of differences in experimental conditions, including the duration of exposure. Furthermore, some authors measured MMR in swimming chambers during steady-state swimming while others used 
static chambers measuring MMR during recovery from an episode of chasing until exhaustion.

During steady swimming, all the components of the oxygen transport chain are solicited and in relative steady state to provide oxygen to the working muscles. On the other hand, following exhaustion, oxygen demanding activities are mostly involved in restoring tissue and cellular homeostasis and steady state in oxygen allocation and use is unlikely (Zhang et al. 2018). Although some evidences suggests that steady swimming and exhaustive exercise can generally give comparable measures of MMR (Killen et al. 2017), it has to be noted that this may depend on the species and its lifestyle. Inter-species variation in the response to hypercapnia should also be expected, especially since Couturier et al. (2013) demonstrated that different species can exhibit different MMR responses to increase $\mathrm{P}_{\mathrm{CO} 2}$.

Following long term exposure to acidification juvenile sea bass displayed significantly lower maximum heart rate $\left(f_{\operatorname{Hax}}\right)(7-15 \%)$ during acute warming than control individuals. It has been recently shown that combining ocean acidification $(1170 \mu \mathrm{atm})$ with increased temperature (from 0 to 8 or $16{ }^{\circ} \mathrm{C}$ in Polar, Boreogadus saida, Lepechin, and Atlantic cod, Gadus morhua, Linnaeus, respectively for 4 weeks) reduced heart mitochondrial ATP production (Leo et al. 2017). This could be one mechanistic reason for the lower maximal heart rate recorded in the hypercapnic fish. However, the present result contrasts with the only other study on cardiac performance following long-term acclimation (14-16 weeks) to hypercapnia (1000 $\mu$ atm) (Gräns et al. 2014). These authors indeed reported that hypercapnia acclimated Atlantic halibut (Hippoglossus hippoglossus, Linnaeus) displayed higher maximum cardiac output than control fish. Because of regulatory change in stroke volume measurement, heart rate and cardiac output do not necessarily correlate. The contrasting results may be resolved by considering a possible compensatory increase in stroke volume. This, indeed, could be the case since there were no differences in the thermal capacities of cardiac function among groups. However, it remains to be tested which are the compensatory 
mechanisms (stroke volume or e.g. changes in energy metabolism of cardiac function). In addition, it has to be acknowledged that in the present study heart rates and metabolic rates were measured several months apart, possibly influencing the relation between them.

Fish exposed to $1490 \mu \mathrm{atm} \mathrm{CO}_{2}$ for 1.5 year displayed heavier gills $(+15 \%)$ and this was not the result of water movements into the gill epithelium as no difference in gill water content with the control group was observed. Although gill surface area was not actually measured, it is tempting to hypothesise that heavier gills indicate increased respiratory surface, as reported in the striped catfish Pangesianodon hypophthalmus (Phuong et al. 2018) and, therefore, increased oxygen extraction capacity. This would also require, however, that the oxygen diffusion distance across the gill epithelium is at least maintained in the high $\mathrm{CO} 2$ treatment. Accordingly, it has been shown that a 14-day exposure of the estuarine red drum (Sciaenops ocellatus) to $1000 \mu \mathrm{atm}$ resulted in a significant reduction in the branchial diffusion distance (Esbaugh et al. 2016). Fish are known for having highly plastic gills, changes having been reported in relation with water oxygenation, temperature, salinity and acidification (Evans et al. 2005; Sollid and Nilsson 2006; Chapman et al. 2008; Rummer et al. 2013). This regulatory mechanism could provide the functional basis for the increased MMR observed in hypercapnic acclimated fish and a compensation for the lower maximal heart rate measured during warming. As maximal heart rate is decreasing, less oxygen may be available to organs, potentially resulting in hypoxemia. Increased gill surface area may have occurred to compensate this phenomenon, leading to increased MMR. Rummer et al (2013) also suggested that the increased MMR they observed in damselfish under acidification condition was obtained via increased gill oxygen extraction capacity, through increased blood perfusion and lamellar recruit. 
Along the same line, fish exposed to acidification displayed higher haemoglobin concentration $\left(+30 \%, 1490 \mu\right.$ atm $\left.\mathrm{P}_{\mathrm{CO} 2}\right)$ and $\mathrm{MCHC}\left(+15 \%, 950\right.$ and $\left.+25 \%, 1490 \mu \mathrm{atm} \mathrm{P}_{\mathrm{CO} 2}\right)$, suggesting higher oxygen carrying capacity than control fish. As no difference in haematocrit was found between treatments, this was obtained without affecting blood viscosity, hence cardiac workload. Similarly, no change in haematocrit has been observed in Gilthead seabream (Sparus aurata, Linnaeus) exposed to $5000 \mu \mathrm{atm} \mathrm{P}_{\mathrm{CO} 2}$ (Michaelidis et al. 2007). In contrast to our results, however, these authors, as well as Rummer et al. (2013), did not find any difference in haemoglobin concentration. Since it can take up to an average of eight months to renew red blood cells stores (Witeska 2013), blood haemoglobin acclimation is a long-term process that may have been missed in short-term acclimation studies.

When exposed to severe hypoxic conditions, hypercapnic-reared fish displayed similar critical oxygen level $\left(\mathrm{O}_{2 \text { crit }}\right)$ than normocapnic fish. The $\mathrm{O}_{2 \text { crit }}$ corresponds to the minimal oxygenation level required to sustain standard metabolic rate $(\mathrm{SMR})$. Below $\mathrm{O}_{2 \text { crit, }}$ aerobic metabolic scope is nil and an increased proportion of fish ATP production shifts from being aerobic to being anaerobic. The only few studies that have investigated the effect of hypercapnia on $\mathrm{O}_{2 \text { crit }}$ were concordant with present results (McKenzie et al. 2003; Couturier et al. 2013; Ern et al. 2017). Other studies have used different indicators to document the transition from aerobic to anaerobic metabolism. Rummer et al. (2013) compared the kinetics of plasma lactate accumulation during an hypoxic episode in the spiny damselfish (Acanthochromis polyacanthus, Bleeker). They found that hypercapnia exposed fish $\left(\mathrm{P}_{\mathrm{CO} 2}=946 \mu \mathrm{atm}\right)$ had similar lactate threshold than control fish. It must be noted, however, that plasma lactate is a difficult indicator to handle as its accumulation in the blood stream is generally the result of the mismatch between production and disposal (Omlin and Weber 2010). Nonetheless, the ability of sea bass juveniles to preserve $\mathrm{O}_{2 \text { crit }}$ under hypercapnic conditions suggests that the implemented physiological adjustments to compensate for extra-cellular 
acidification did not affect fish capacity to meet maintenance oxygen demand under reduced oxygen availability. This is an important result as potential trade-off between hypoxia tolerance and high oxygen transport capacity and aerobic metabolism might arise from conflicting influence of haemoglobin oxygen affinity (Burggren et al. 1991). It is interesting to point out that in the present study such trade-off didn't seem to occur as no difference was observed in fish capacity to maintain aerobic metabolism under hypoxia $\left(\mathrm{O}_{2 \text { crit }}\right)$ while increasing aerobic capacity (MMR).

\section{CONCLUSION}

Long-term, across life-stages exposure to acidification levels predicted for 2100 (Caldeira and Wickett 2005; Intergovernmental Panel on Climate Change 2014) resulted in a new aerobic metabolic condition in the sea bass, Dicentrarchus labrax (Linnaeus) juveniles. Fish from the high acidification condition (1490 $\mu \mathrm{atm})$ had higher aerobic capacities (MMR) which correlated with heavier gills and increased blood haemoglobin concentration, suggesting potentially higher oxygen extraction and transport capacity, even if lower maximal heart rate during warming. These results suggest that sea bass juveniles have some metabolic capacities to face projected acidification scenarios. However, further experiments are needed to investigate more deeply the underlying mechanisms involved in the acclimation process. Measurements of extra- and intra-cellular $\mathrm{pH}$ and bicarbonate concentration, as well as activities of transporters involved in acid-base regulation, should be conducted to confirm that acid-base balance was fully restored under acidified condition. Moreover, even though the oxygen threshold below which an increased proportion of ATP production shifts from being aerobic to being anaerobic was not affected by hypercapnia, it may have affected fish anaerobic metabolic capacity (Claireaux and Chabot, 2016). In addition, ocean acidification represents just one component of global climate change together with, for instance, ocean warming and deoxygenation. Therefore, there is a pressing need to examine the synergistic 
564 effect of these stressors, as some studies revealed that together they have stronger impacts on

565 marine organisms than when occurring alone (Enzor et al. 2013; Leo et al. 2017). These

566 investigations are essential to provide strong physiological basis and allow a better understanding of

567 the possible adaptation of fish populations in a changing world.

568

569 Compliance with Ethical Standards

570

571 Conflict of Interest The authors declare no competing or financial interests

572

573 Ethical approval All applicable international, national, and/or institutional guidelines for the

574 care and use of animals were followed. Project code: APAFIS 4341.03, \#201620211505680.V3

575

576 Author contributions

577 Conceptualization: AC, KA, GC

578 Methodology: AC, KA, GC

579 Software: DC

580 Formal analysis: PL, AC, KA

581 Resources: PQ, NLB, ZLZI, GC

582 Writing - original draft: PL, AC

583 Writing - review and editing: AC, KA, GC, PL, JLZI, DC

584 Supervision: AC, JLZI, GC

585 Project administration: JLZI, GC

586 Funding acquisition: JLZI, GC 


\section{REFERENCES}

Aminot A, Kerouel R, Coverly S (2009) Nutrients in seawater using segmented flow analysis Practical guidelines for the analysis of seawater. CRC Press, Boca Raton, pp 143-178

Anttila K, Casselman MT, Schulte PM, Farrell AP (2013) Optimum temperature in juvenile salmonids: connecting subcellular indicators to tissue function and whole-organism thermal optimum. Physiological and Biochemical Zoology 86: 245-256. doi: 10.1086/669265

Bresolin de Souza K, Jutfelt F, Kling P, Förlin L, Sturve J (2014) Effects if increased $\mathrm{CO}_{2}$ on fish gill and plasma proteome. PLoS ONE 9: e102901.

Burggren W, McMahon B, Powers D (1991) Respiratory functions of blood. In: Prosser CL (ed) Environmental and metabolic animal physiology, New York, pp 437-508

Caldeira K, Wickett ME (2005) Ocean model predictions of chemistry changes from carbon dioxide emissions to the atmosphere and ocean. Journal of Geophysical Research 110: C09S04. doi: 10.1029/2004JC002671

Casselman MT, Anttila K, Farrell AP (2012) Using maximum heart rate as a rapid screening tool to determine optimum temperature for aerobic scope in Pacific salmon Oncorhynchus spp. Journal of Fish Biology 80: 358-377. Doi: 10.1111/j.1095-8649.2011.03182.x.

Chabot D, Steffensen JF, Farrell AP (2016) The determination of standard metabolic rate in fishes. Journal of Fish Biology 88: 81-121.

Chapman L, Albert J, Galis F (2008) Developmental plasticity, genetic differenciation, and hypoxia-induced trade-offs in an African cichlid fish. The Open Evolution Journal 2: 75-88.

Claireaux G, Chabot D (2016) Responses by fishes to environmental hypoxia: integration through Fry’s concept of aerobic metabolic scope. Journal of Fish Biology 88: 232-251. 
Claireaux G, Lefrançois C (2007) Linking environmental variability and fish performance: integration through the concept of scope for activity. Philosophical Transactions of the Royal Society B: Biological Sciences 362: 2031-2041.

Couturier CS, Stecyk JAW, Rummer JL, Munday PL, Nilsson GE (2013) Species-specific effects of near-future $\mathrm{CO} 2$ on the respiratory performance of two tropical prey and their predator. Comparative Biochemistry and Physiology 166: 482-489.

Crespel A, Zambonino-Infante JL, Mazurais D, Koumoundouros G, Fragkoulis S, Quazuguel P, Huelvan C, Madec L, Servili A, Claireaux G (2017) The development of contemporary European sea bass larvae (Dicentrarchus labrax) is not affected by projected ocean acidification scenarios. Marine Biology 164doi: 10.1007/S00227-017-3178-X

Deigweiher K, Hirse T, Bock C, Lucassen M, Pörtner HO (2010) Hypercapnia induced shifts in gill energy budgets of Antarctic notothenioids. Journal of Comparative Physiology BBiochemical Systemic and Environmental Physiology 180: 347-359.

Deigweiher K, Koschnick N, Pörtner HO, Lucassen M (2008) Acclimation of ion regulatory capacities in gills of marine fish under environmental hypercapnia. American Journal of Physiology-Regulatory Integrative and Comparative Physiology 295: R1660-R1670.

Dickson AG, Sabine CL, Christian JR (2007) Guide to best practices for ocean CO2 measurments. PICES Special Publications 3, pp 191

Enzor LA, Zippay ML, Place SP (2013) High latitude in a high CO2 world: Synergistic effects of elevated temperature and carbon dioxide on the metabolic rates of Antarctic notothenioids. Comparative Biochemistry and Physiology A-Molecular \& Integrative Physiology 164: 154161.

Ern R, Johansen JL, Rummer JL, Esbaugh AJ (2017) Effects of hypoxia and ocean acidification on the upper thermal niche boundaries of coral reef fishes. Biology Letters 13Artn 20170135

doi: $10.1098 / \mathrm{Rsbl} .2017 .0135$ 
Esbaugh AJ (2018) Physiological implications of ocean acidification for marine fish: emerging patterns and new insights. Journal of Comparative Physiology B-Biochemical Systemic and Environmental Physiology 188: 1-13. doi: 10.1007/s00360-017-1105-6

Esbaugh AJ, Ern R, Nordi WM, Johnson AS (2016) Respiratory plasticity is insufficient to alleviate blood acid-base disturbances after acclimation to ocean acidification in the estuarine red drum, Sciaenops ocellatus. Journal of Comparative Physiology B-Biochemical Systemic and Environmental Physiology 186: 97-109. doi: 10.1007/s00360-015-0940-6

Esbaugh AJ, Heuer R, Grosell M (2012) Impacts of ocean acidification on respiratory gas exchange and acid-base balance in a marine teleost, Opsanus beta. Journal of Comparative Physiology B-Biochemical Systemic and Environmental Physiology 182: 921-934. doi: $10.1007 / \mathrm{s} 00360-012-0668-5$

Evans DH, Piermarini PM, Choe KP (2005) The multifunctional fish gill: dominant site of gas exchange, osmoregulation, acid-base regulation, and excretion of nitrogenous waste. Physiological Review 85: 97-177.

Farrell AP, Eliason EJ, Clark TD, Steinhausen MF (2014) Oxygen removal from water versus arterial oxugen delivery: calibrating the Fick equation in Pacific salmon. Journal of Comparative Physiology B-Biochemical Systemic and Environmental Physiology 184: 855864. doi: 10.1007/s00360-014-0839-7

Fry FEJ (1971) The effect of environmental factors on the physiology of fish. In: Hoar WS, Randall, D.J. (ed) Fish physiology. Academic Press, New York pp 1-98

Gräns A, Jutfelt F, Sandblom E, Jönsson E, Wiklander K, Seth H, Olsson C, Dupont S, OrtegaMartinez O, Einarsdottir I, al. e (2014) Aerobic scope fails to explain the detrimental effets on growth resulting from warming and elevated $\mathrm{CO}_{2}$ in Atlantic halibut. Journal of Experimental Biology 217: 711-717. 
Hannan KD, Rummer JL (2018) Aquatic acidification: a mechanism underpinning maintained oxygen transport and perforamnce in fish epeiencting elevated carbon dioxide conditions. Journal of Experimental Biology 221: jeb154559. doi:10.1242/jeb.154559

Heuer RM, Grosell M (2014) Physiological impacts of elevated carbon dioxide and ocean acidification on fish. American Journal of Physiology-Regulatory Integrative and Comparative Physiology 307: R1061-R1084. doi: 10.1152/ajpregu.00064.2014.

Intergovernmental Panel on Climate Change I (2014) Climate change 2014: Synthesis Report. In: CoreWritingTeam, Pachauri RK, Meyer LA (eds) Contribution of working groups I, II and III to the fifth assessment report of the the intergovernmental panel on climate change. IPCC, Geneva, Switzerland, pp 151

Jourdan-Pineau H, Dupont-Prinet A, Claireaux G, McKenzie D (2010) An

Investigation of Metabolic Prioritization in the European Sea Bass, Dicentrarchus labrax. Physiological and Biochemical Zoology 83: 68-77.

Killen SS, Norin T, Halsey LG (2017) Do methods and species lifestyle affect measures of maximum metabolic rate in fishes? Journal of Fish Biology 90: 1037-1046.

Kroeker KJ, Kordas RL, Crim RN, Hendriks IE, Ramajo L, Singh GS, Duarte CM, Gattuso JP (2013) Impacts of ocean acidification on marine organisms: quantifying sensitivities and interaction with warming. Global Change Biology 19: 1884-1896.

Kroeker KJ, Kordas RL, Crim RN, Singh GG (2010) Meta-analysis reveals negative yet variable effects of ocean acidification on marine organisms. Ecology Letters 13: 1419-1434. doi: 10.1111/j.1461-0248.2010.01518.x

Lefevre S (2016) Are global warming and ocean acidification conspiring against marine ectotherms? A meta-analysis of the respiratory effects of elevated temperature, high $\mathrm{CO} 2$ and their interaction. Conservation Physiology 4: cow009. doi:10.1093/conphys/cow009 
Leo E, Kunz KL, Schmidt M, Storch D, Portner HO, Mark FC (2017) Mitochondrial acclimation potential to ocean acidification and warming of Polar cod (Boreogadus saida) and Atlantic cod (Gadus morhua). Frontiers in Zoology 14: 21. Doi: https://doi.org/10.1186/s12983-0170205-1

Lewis E, Wallace DWR (1998) Program developed for CO2 system calculations., ORNL/CDIAC105. Carbon Dioxide Information Analysis Center, Oak Ridge National Laboratory, U. S. Department of Energy, Oak Ridge, Tennessee

Lüthi D, Le Floch M, Bereiter B, Blunier T, Barnola JM, Siegenthaler U, Raynaud D, Jouzel J, Fischer H, Kawamura K, Stocker TF (2008) High-resolution carbon dioxide concentration record 650,000-800,000 years before present. Nature 453: 379-382. doi: 10.1038/nature06949.

McKenzie D, Piccolella M, Valle AZD, Taylor EW, Bolis CL, Steffensen JF (2003) Tolerance of chronic hypercapnia by the European ell Anguilla anguilla. Journal of Experimental Biology 206: $1717-1726$.

Mehrbach C, Culberson CH, Hawley JE, Pytkowicx RM (1973) Measurment of the apparent dissociation constants of carbonic acid in seawater at atmospheric pressure. Limnology and Oceanography 18: 897-907.

Melzner F, Göbel S, Langenbuch M, Gutowska MA, Portner HO, Lucassen M (2009) Swimming performance in Atlantic cod (Gadus morhua) following long-term (4-12 months) acclimation to elevated seawater $\mathrm{P}(\mathrm{CO} 2)$. Aquatic Toxicology 92: 30-37.

Michaelidis B, Spring A, Portner HO (2007) Effects of long-term acclimation to environmental hypercapnia on extracellular acid-base status and metabolic capacity in Mediterranean fish Sparus aurata. Marine Biology 150: 1417-1429. DOI 10.1007/s00227-006-0436-8 
Nilsson GE, Renshaw GM (2004) Hypoxic survival strategies in two fishes: extreme anoxia tolerance in the North European Crucian carp and natural hypxic preconditionning in a coral-reef shark. Journal of Experimental Biology 207: 3131-3139.

Omlin T, Weber JM (2010) Hypoxia stimulates lactate disposal in rainbow trout. Journal of Experimental Biology 213: 3802-3809. doi: 10.1242/jeb.048512

Phuong LM, Huong DTT, Malte H, Nyengaard JR, Bayley M (2018) Ontogeny and morphometrics of the gills and swim bladder of air-breathing striped catfish Pangasianodon hypophthalmus. Journal of Experimental Biology 221UNSP jeb168658

doi: $10.1242 /$ jeb. 168658

Pörtner HO, Farrell AP (2008) Physiology and climate change. Science 322: 690-692.

Pörtner HO, Langenbuch M, Reipschlager A (2004) Biological impact of elevated ocean CO2 concentrations: lessons from animal physiology and earth history. Journal of Oceanography 60: 705-718. doi: 10.1007/s10872-004-5763-0

Rogers NJ, Urbina MA, Reardon EE, McKenzie D, Wilson R (2016) A new analysis of hypoxia tolerance in fishes using a database of critical oxygen level $\left(P_{\text {crit }}\right)$. Conservation Physiology 4: cow012. doi: 10.1093/conphys/cow012

Rummer JL, Stecyk JAW, Couturier CS, Watson SA, Nilsson G, Munday PL (2013) Elevated CO 2 enhances aerobic scope of a coral reef fish. Conservation Physiology 1: $\cot 023$.

Schmidt-Nielsen K (1997) Animal physiology: adaptation and environment. University Press, Cambridge

Sollid J, Nilsson GE (2006) Plasticity of respiratory structures - Adaptive remodeling of fish gills induced by ambient oxygen and temperature. Respiratory Physiology and Neurobiology 154: 241-251. doi:10.1016/j.resp.2006.02.006

Vanderplancke G, Claireaux G, Quazuguel P, Madec L, Ferraresso S, Sévère A, Zambonino-Infante JL, Mazurais D (2015) Hypoxic episode during larval period has long-term effects on 

European sea bass juveniles (Dicentrarchus labrax). Marine Biology 162: 367-376. doi: $10.1007 / \mathrm{s} 00227-014-2601-9$

734 Witeska M (2013) Erythrocytes in teleost fishes: a review. Zoology and Ecology 23: 275-281. doi: 735 $10.1080 / 21658005.2013 .846963$ exercise oxygen consumption in Atlantic salmon Salmo salar and its response to exercise training. Journal of Fish Biology 92doi: 10.1111/jfb.13593 
Chasing

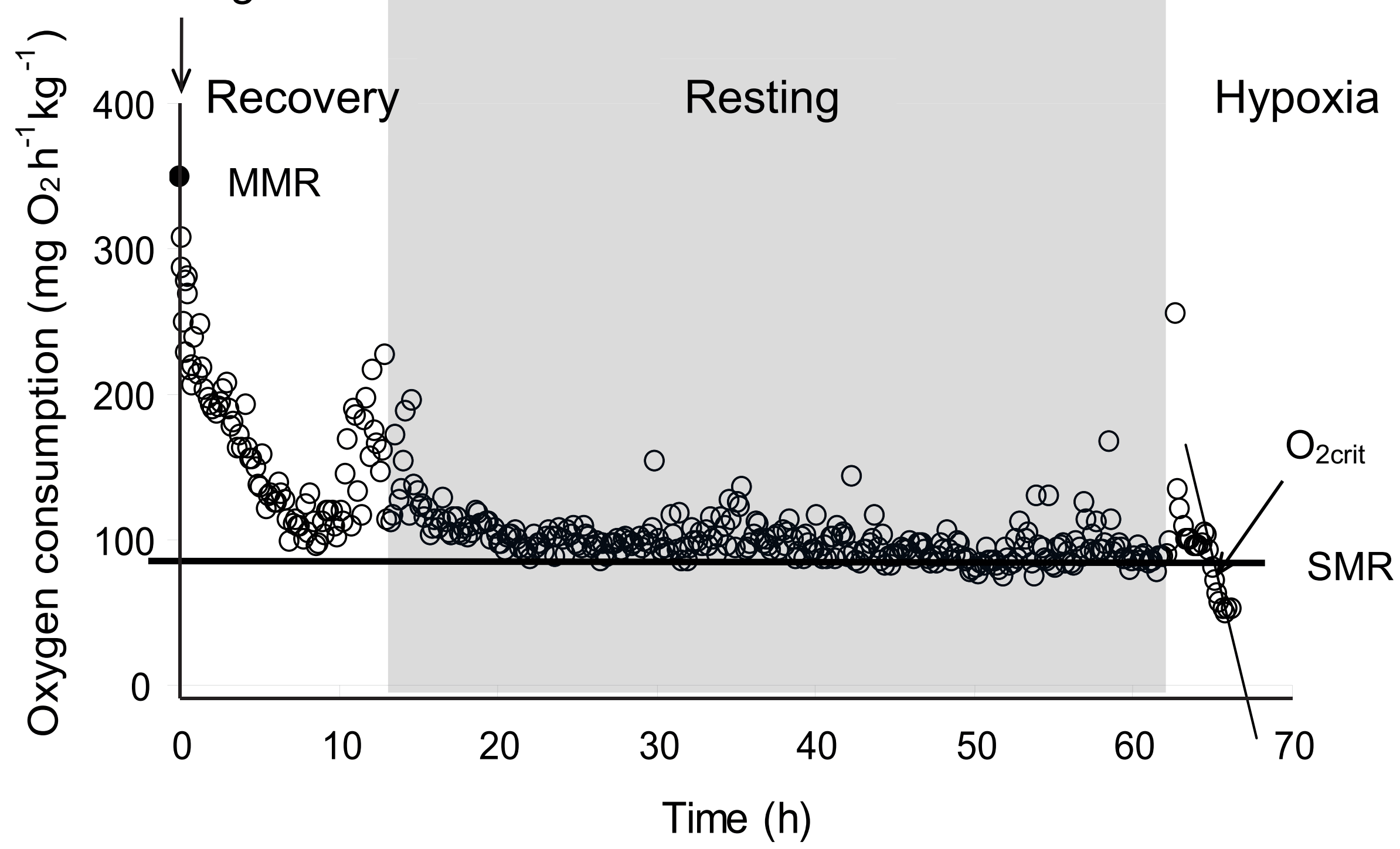




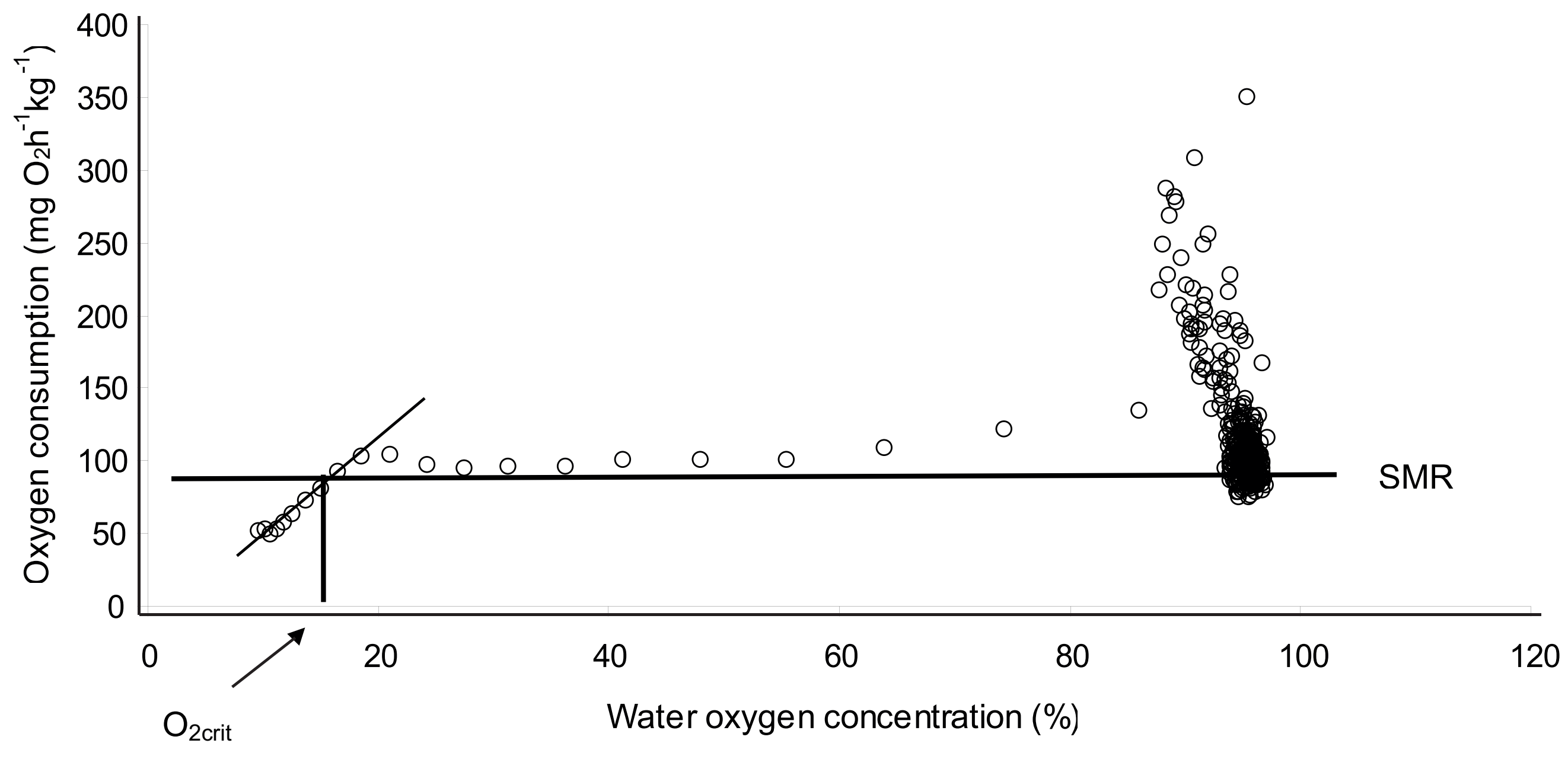




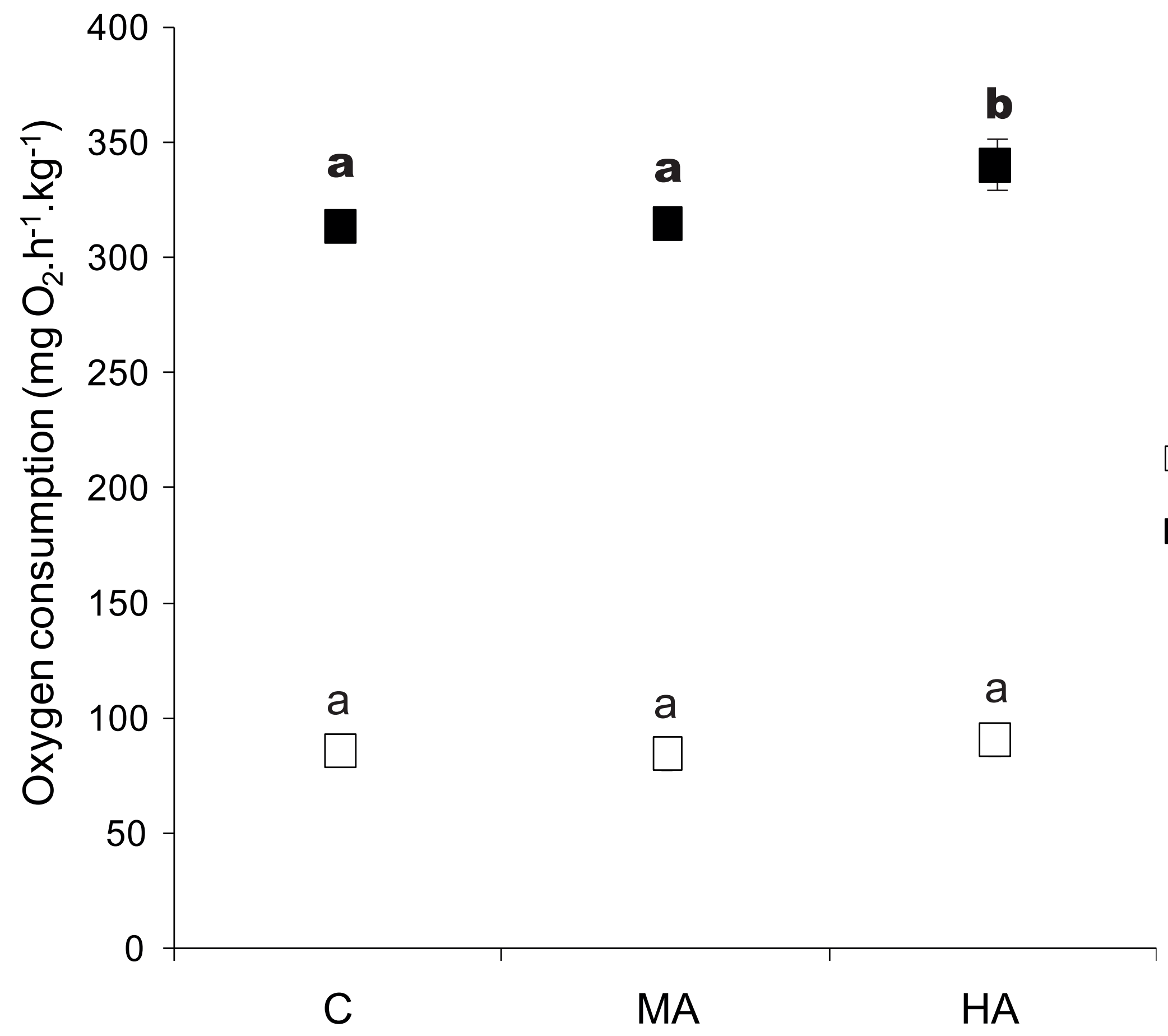

$\square$ SMR

- MMR

HA 


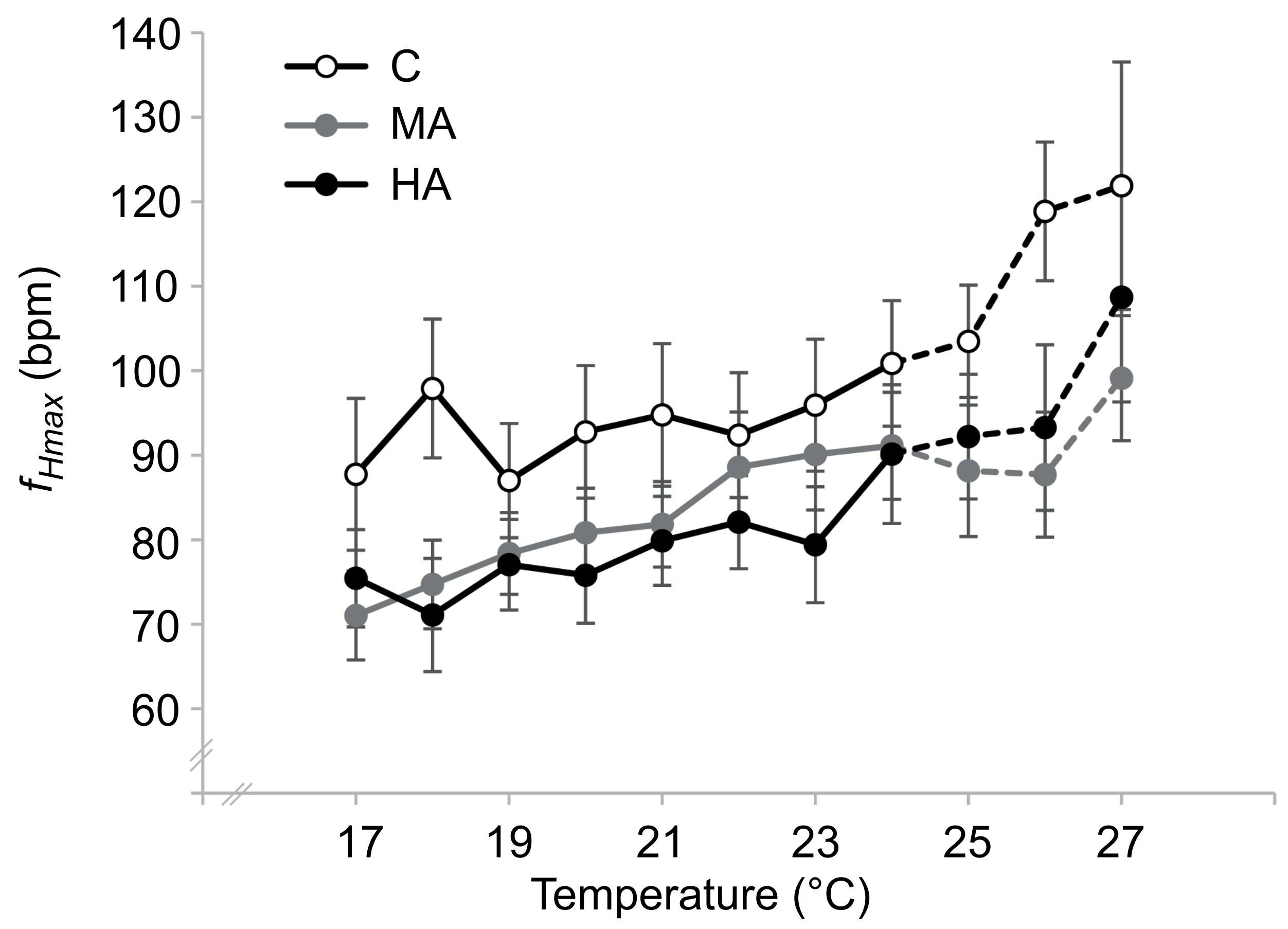




\section{Figure captions}

2

3 Fig. 1 Oxygen consumption $\left(\mathrm{mg} \mathrm{O}_{2} \mathrm{~h}^{-1} \mathrm{~kg}^{-1}\right)$ over time (h) of a typical fish. Fish were first chased until exhaustion (Chasing) to determine the maximal metabolic rate (MMR). Then fish were allowed to rest over a period of $65 \mathrm{~h}$ (Resting) to determine the standard metabolic rate (SMR). Finally, fish were exposed to a progressive hypoxia (Hypoxia) to determine the fish critical oxygen $\operatorname{limit}\left(\mathrm{O}_{2}\right.$ crit $)$.

Fig. 2 Oxygen consumption $\left(\mathrm{mg} \mathrm{O}_{2} \mathrm{~h}^{-1} \mathrm{~kg}^{-1}\right)$ over water oxygen concentration (\%) of a typical fish. Fish were exposed to a progressive hypoxia to determine the fish critical oxygen limit $\left(\mathrm{O}_{2 \text { crit }}\right)$. When ambient oxygen drops below $\mathrm{O}_{2 \text { crit }}$, fish $\mathrm{MO}_{2}$ decline proportionally and reveal a linear regression (LR) between oxygen level and $\mathrm{MO}_{2}$ at the end of hypoxia. The intersection between the regression line and the horizontal line corresponding to $\mathrm{SMR}$ was $\mathrm{O}_{2 \text { crit. }}$

Fig. 3 The oxygen consumption $\left(\mathrm{mg} \mathrm{O}_{2} \mathrm{~h}^{-1} \mathrm{~kg}^{-1}\right)$ in the fish exposed to control $\mathrm{P}_{\mathrm{CO} 2}(\mathrm{C} ; 520 \mathrm{ppm})$, moderate hypercapnia (MA; 950 ppm) and high hypercapnia (HA; 1490 ppm). Standard ( $\square$ SMR) and maximal ( $\square$ MMR) metabolic rates of fish exposed during 1.5-year. Values are mean \pm s.e.m., $n$ $=22$ to 24 per group. The oxygen consumption was analysed using the absolute values (in $\mathrm{mg} \mathrm{O}_{2} \mathrm{~h}^{-}$ ${ }^{1}$ ) and body mass as a covariate, the data are presented as mass-specific for clarity. Different letters indicate significant differences $(\mathrm{P}<0.05)$.

Fig. 4 The maximum heart rate $\left(f_{\text {Hmax }}\right)$ values of fish exposed to control $\mathrm{P}_{\mathrm{CO} 2}(\mathrm{C} ; 520 \mathrm{ppm})$, moderate hypercapnia (MA; 950 ppm) and high hypercapnia (HA; 1490 ppm) during incremental warming. The $f_{\text {Hmax }}$ was achieved by intraperitoneal injections of atropine sulphate and isoproterenol. The heating rate was $10^{\circ} \mathrm{C} \mathrm{h}^{-1}$. Values are mean beats per minute (bpm) \pm (s.e.m.), $\mathrm{n}$ 
$26=14$ per group. There is significant differences between $C$ and $M A(\mathrm{P}<0.001, \mathrm{~T}=4.0)$ and

27 between $C$ and $H A(\mathrm{P}<0.001, \mathrm{~T}=4.9)$ while the $M A$ and $H A$ did not differed significantly from

28 each other $(\mathrm{P}=0.68, \mathrm{~T}=0.4)$. The dotted lines indicate temperatures at which arrhythmias were 29 observed in individual fish.

30

31 Fig. 5 The gill responsein the fish exposed to control $\mathrm{P}_{\mathrm{CO} 2}(\mathrm{C} ; 520 \mathrm{ppm})$, moderate hypercapnia 32 (MA; 950 ppm) and high hypercapnia (HA; 1490 ppm). (A) Dry gill mass to body mass ratio and 33 (B) gill water content of fish exposed during 1.5-year. Values are mean \pm s.e.m., $\mathrm{n}=8$ per group. 34 Different letters indicates significant difference $(\mathrm{P}<0.05)$.

35 
1 Table 1 Water chemistry of the experimental tanks. Water temperature $\left(\mathrm{T}^{\circ} \mathrm{C}\right), \mathrm{pH}$ NBS $(\mathrm{NBS}$

2 scale), $\mathrm{pH}$ tot (total scale), $\mathrm{TA}$ (total alkalinity), $\mathrm{PO}_{4}{ }^{3-}$ (phosphate concentration), $\mathrm{SiO}_{4}$ ( silicate

3 concentration) were measured in the different conditions. $\mathrm{P}_{\mathrm{CO} 2}$ (the projected partial pressure of

$4 \quad \mathrm{CO}_{2}$ ) was calculated using CO2SYS software in the different conditions.

5

\begin{tabular}{ccccccccc}
\hline & Salinity (\%o) & $\mathrm{T}^{\circ} \mathrm{C}$ & $\mathrm{pH}$ NBS & $\mathrm{pH}$ tot & $\mathrm{TA}\left(\mu \mathrm{ML}^{-1}\right)$ & $\mathrm{PO}_{4}^{3-}\left(\mu \mathrm{ML}^{-1}\right)$ & $\mathrm{SiO}_{4}\left(\mu \mathrm{ML}^{-1}\right)$ & $\mathrm{P}_{\mathrm{CO} 2}(\mu \mathrm{atm})$ \\
& $\mathrm{n}=5$ & $\mathrm{n}=525$ & $\mathrm{n}=525$ & $\mathrm{n}=5$ & $\mathrm{n}=9$ & $\mathrm{n}=6$ & $\mathrm{n}=6$ & $\mathrm{n}=9$ \\
& & & & & & & & \\
\hline $\mathrm{C}$ & $34.3(0.2)$ & $15.3(0.1)$ & $8.05(0.01)$ & $7.94(0.03)$ & $2294(10)$ & $0.71(0.08)$ & $8.35(0.26)$ & $516(31)$ \\
$\mathrm{MA}$ & $34.3(0.2)$ & $15.3(0.1)$ & $7.82(0.01) 7.71(0.02)$ & $2293(14)$ & $0.71(0.08)$ & $8.35(0.26)$ & $953(28)$ \\
$\mathrm{HA}$ & $34.3(0.2)$ & $15.3(0.1)$ & $7.61(0.01) 7.53(0.02)$ & $2280(16)$ & $0.71(0.08)$ & $8.35(0.26)$ & $1489(42)$
\end{tabular}

$6 \quad$ Values are mean \pm (s.e.m.), $\mathrm{n}$ is the number of samples 
8 Table 2 The Arrhenius break point temperature $\left(\mathrm{T}_{\mathrm{AB}}\right)$ and arrhythmia temperature $\left(\mathrm{T}_{\mathrm{ARR}}\right)$ of fish

9 exposed during 1.5-year to control $\mathrm{P}_{\mathrm{CO} 2}(\mathrm{C} ; 520 \mathrm{ppm})$, moderate hypercapnia (MA; $\left.950 \mathrm{ppm}\right)$ and 10 high hypercapnia (HA; 1490 ppm).

11

\begin{tabular}{lcc}
\hline & $\mathbf{T}_{\text {AB }}\left({ }^{\circ} \mathbf{C}\right)$ & $\mathbf{T}_{\text {ARR }}\left({ }^{\circ} \mathbf{C}\right)$ \\
\hline $\mathbf{C}$ & $21.5(0.5)$ & $25.7(0.8)$ \\
MA & $21.5(0.5)$ & $26.6(0.5)$ \\
HA & $21.6(0.5)$ & $25.9(0.6)$
\end{tabular}

12 Values are mean \pm (s.e.m.), $\mathrm{n}=14$ per group. No significant differences were found between 13 groups. 
Table 3 Ventriculo-somatic index (VSI), blood haematocrit (Hct), blood haemoglobin concentration $(\mathrm{Hb})$, mean corpuscular haemoglobin concentration (MCHC) and critical oxygen

17 level $\left(\mathrm{O}_{2 \text { crit }}\right)$ of fish exposed during 1.5-year to control $\mathrm{P}_{\mathrm{CO} 2}(\mathrm{C} ; 520 \mathrm{ppm})$, moderate hypercapnia 18 (MA; 950 ppm) and high hypercapnia (HA; 1490 ppm).

19

\begin{tabular}{|c|c|c|c|c|c|}
\hline & VSI (\% body mass) & Hct $(\%)$ & Hb $\left(\mathrm{mgdL}^{-1}\right)$ & MCHC $\left(\mathrm{mgdL}^{-1}\right)$ & $\mathbf{O}_{2 \text { crit }}(\%)$ \\
\hline $\mathrm{C}$ & $0.053(0.001)$ & $35.1(1.6)$ & $7.3(0.4)^{\mathrm{a}}$ & $20.9(1.2)^{\mathrm{a}}$ & $17.8(0.5)$ \\
\hline MA & $0.055(0.004)$ & $32.6(1.7)$ & $7.9(0.4)^{\mathrm{a}}$ & $24.2(0.3)^{\mathrm{b}}$ & $17.1(0.5)$ \\
\hline HA & $0.058(0.001)$ & $35.5(1.3)$ & $9.4(0.4)^{b}$ & $26.4(0.6)^{\mathrm{b}}$ & $16.8(0.5)$ \\
\hline
\end{tabular}

20 Values are mean \pm (s.e.m.), $n=24$ per group. Different letters indicates significant difference 21 among groups $(\mathrm{P}<0.05)$. 